\title{
Assessment of the degree of conversion in light-curing orthodontic resins with various viscosities
}

\author{
Lorenna Oliveira Fernandes de Araujo', Osmar Barreto ${ }^{2}$, Adriano Augusto Melo de Mendonça' \\ and Rodrigo França ${ }^{3^{*}}$
}

\section{*Correspondence:}

rodrigo.franca@umanitoba.ca

${ }^{3}$ Dental Biomaterials

Research Lab, Department

of Restorative Dentistry,

College of Dentistry, Faculty

of Health Sciences, University of Manitoba, D232 Dental

Building, 780 Bannatyne Avenue, Winnipeg, MB R3E OW2, Canada

Full list of author information is available at the end of the article

\begin{abstract}
Objective: The aim of this study was to determine the degree of conversion (DC) for five orthodontic resins with different viscosities, to examine a probable relationship between the viscosity factor and the degree of conversion of the materials.
\end{abstract}

Methods: Five commercially-available light-cured orthodontic bonding resins were used in this study: two medium viscosity resins [transbond XT (TR); opal bond MV (OB)]; two low viscosity resins [vertise flow (VF); opal bond flow (OF)]; and a fluoride-releasing sealant [opal seal (OS)]. The specimens were made and polymerized for $20 \mathrm{~s}$. Fourier Transformed Infrared spectroscopy (FTIR) was used to assess the DC of carbon-carbondouble bonds from all samples.

Results: The DC was significantly different among the materials: (TR, $24.6 \pm 0.04 \%$; $\mathrm{OB}, 39 \pm 0.02 \% ; \mathrm{VF}, 44.3 \pm 0.01 \% ; \mathrm{OS}, 52.5 \pm 0.01 \% ; \mathrm{OF}, 53 \pm 0.04 \% ; \mathrm{p}<0.05)$ and the lowest viscosity materials had the highest DC values.

Conclusion: The resins studied have different DC values, which can be explained by the unique composition of each brand of resin. There is a relationship between the viscosity of a material and its degree of conversion, which is shown in this study by the two low-viscosity orthodontic resins that had a higher DC.

Keywords: Degree of conversion, Orthodontics resins, Viscosity

\section{Background}

A wide variety of orthodontic resins are currently being used clinically for the bonding of orthodontic brackets, orthodontic bands and fixation of lingual appliances. Among the options available on the dental market, resin composite adhesives are a good choice for orthodontic bonding because these materials have good mechanical and aesthetic properties and low failure rates [1]. Orthodontic resin-based adhesives with photo-activation properties are a widely accepted group of composites in the profession because of their advantages such as high early bond strength, better aesthetic performance and controlled working time [2, 3].

Recently, flowable or low viscosity composites have been applied for orthodontic use by many clinicians. However, there are few studies available on this type of composite, and its characteristics and interactions with the enamel surfaces and the oral cavity.

(C) 2015 de Araujo et al. This article is distributed under the terms of the Creative Commons Attribution 4.0 International License (http://creativecommons.org/licenses/by/4.0/), which permits unrestricted use, distribution, and reproduction in any medium, provided you give appropriate credit to the original author(s) and the source, provide a link to the Creative Commons license, and indicate if changes were made. 
Flowable composites are produced by retaining the same small particle sizes as for traditional hybrid composites and reducing the filler content, which allows a decrease in the mixture viscosity [4].

Studying the degree of conversion (DC) of orthodontic resins and its relationship with material viscosity is important to determine if different brands of resin composites show different leaching abilities for unpolymerized components, and thus present different potentials for toxicity to cells in the mouth [5]. Studies show that components released by dental resin composites, including diluents such as triethylene glycol dimethacrilate (TEGDMA), some additives, plasticizers (dicyclohexyl phthalate; bis (2-ethylhexyl) phthalate), can make collagen and protein found in the oral cavity and throughout the human body less resistant to enzymatic degradation. In addition, the resin composite co-monomer, TEGDMA, can cause gene mutation in vitro [5-7]. Thus, materials that have a higher degree of dissolution and/or chemical degradation do not seem to be the best choice for a clinician. Therefore, mechanical and physical properties of new materials need to be studied, to validate their safety when used in the oral environment.

Thus, the purpose of this study is to investigate the DC of five commercially available light-cured orthodontic resins that present different viscosities. The results may determine a relationship between the viscosity and the DC of the materials.

\section{Methods}

Five brands of light-cured orthodontic bonding systems with different viscosities were selected for this study. Commercial names, viscosities and composition indicated by the manufacturers of these materials are shown in Table 1. A total of 25 specimens were produced, 5 for each brand of composite used in this experiment $(n=5)$.

The specimens, $5 \mathrm{~mm}$ in diameter and $2 \mathrm{~mm}$ in length, were made at room temperature using a silicon mold. After placing a small amount of material into the mold, a Mylar strip was placed on top of the unpolymerized material and a 4-mm-thick glass slide was pressed on top of the silicon mold. This process was repeated for all brands of resin.

Each specimen was polymerized for $20 \mathrm{~s}$ using a LED light-curing unit (VALO, Ultradent), The light intensity was $1000 \mathrm{~mW} / \mathrm{cm}^{2}$, the amount of time and energy provide for light curing were above the minimum required by the manufactures. A glass

Table 1 Material identification

\begin{tabular}{|c|c|c|c|c|}
\hline Material & Code & Viscosity & Basic ingredients & Manufacturer \\
\hline Transbond $X T^{\circledR}$ & $\mathrm{TR}$ & Medium viscosity & $\begin{array}{l}\text { Bis-GMA, Bis-EMA, silane- } \\
\text { treated quartz, silane- } \\
\text { treated silica }\end{array}$ & $\begin{array}{l}\text { 3M Unitek, Monrovia, CA, } \\
\text { USA }\end{array}$ \\
\hline Opal Bond MV ${ }^{\circledR}$ & $\mathrm{OB}$ & Medium viscosity & $\begin{array}{l}\text { Bis GMA, ethyl 4-dimethyl- } \\
\text { aminobenzoate }\end{array}$ & $\begin{array}{l}\text { Ultradent, South Jordan, } \\
\text { UT, USA }\end{array}$ \\
\hline Vertise Flow ${ }^{\circledR}$ & VF & Low viscosity & $\begin{array}{l}\text { Uncured methacrylate } \\
\text { ester monomers, inert } \\
\text { mineral fillers, ytterbium } \\
\text { fluoride, activators, } \\
\text { stabilizers, colorants }\end{array}$ & Kerr, Orange, CA, USA \\
\hline Opal Bond Flow ${ }^{\circledR}$ & OF & Low viscosity & $\begin{array}{l}\text { Bis GMA, ethyl 4-dimethyl- } \\
\text { aminobenzoate }\end{array}$ & $\begin{array}{l}\text { Ultradent, South Jordan, } \\
\text { UT, USA }\end{array}$ \\
\hline Opal Seal ${ }^{\circledR}$ & OS & $\begin{array}{l}\text { Orthodontic Sealant (38 \% } \\
\text { filled bonding primer) }\end{array}$ & Ethyl alcohol, HPMA & $\begin{array}{l}\text { Ultradent, South Jordan, } \\
\text { UT, USA }\end{array}$ \\
\hline
\end{tabular}


slide $(1 \mathrm{~mm})$ was used to standardize the distance between the light source and each specimen, and also to produce specimens with a flat surface. Immediately after polymerization, the samples were subjected to Fourier transform infrared (FTIR) spectroscopy analysis.

Non-cured resin specimens were also subjected to FTIR spectroscopy, to serve as non-cured references. Each sample was placed directly on top of the device's crystal for prompt analysis. The degree of polymerization was monitored by the FTIR spectroscopic analysis in transmission mode, and then converted to absorbance mode, using the device's software. The FTIR spectrometer (Nicolet 6700, Thermo Scientific) ran under the following conditions: $4000-400 \mathrm{~cm}^{-1}$ wavenumber range $0.09 \mathrm{~cm}^{-1}$ resolution and 32 scans.

The DC was obtained using the results from the spectroscopic analysis. The DC was calculated using the formula shown in Fig. 1. The equation correlates the absorbance value of the aliphatic $C=C$ peak approximately at $1638 \mathrm{~cm}^{-1}$ with the aromatic $\mathrm{C}-\mathrm{C}$ peak at approximately $1609 \mathrm{~cm}^{-1}$, for the samples before and after polymerization. Statistical analysis was performed using a one-way analysis of variance (ANOVA) and Tukey's post hoc test at a significance level of $5 \%$.

\section{Results}

There were significant differences in the degree of polymerization for the resins in this study ( $<0.05)$. The DC was calculated using the FTIR analysis results from each sample, and then determining the percentage for each group of samples. The mean values (MV) and their standard deviations (SD) are presented in Table 2 and illustrated in Fig. 2.

Based on the mean values of conversion recorded for each material, the materials with a lower viscosity showed a higher degree of polymerization than those with higher viscosity.

TR had the lowest mean DC value (24.6\%), which was significantly different than the other materials $(\mathrm{p}<0.05)$. The DC results were $39,44.3$ and $52.5 \%$ for OB, VF and OS, respectively. There were no significant differences between the mean values of $O B$ and

$$
\mathrm{DC} \%=1-\left[\frac{\mathrm{C}_{\text {aliphatic }} / \mathrm{C}_{\text {aromatic }}}{\mathrm{U}_{\text {aliphatic }} / \mathrm{U}_{\text {aromatic }}}\right] .100
$$

Fig. 1 Equation to determine the degree of conversion

Table 2 DC mean values and standard deviation

\begin{tabular}{lrr}
\hline Resins & MV (\%)/SD & St* $^{*}$ \\
\hline TR & $24.6( \pm 4.67)$ & $\mathrm{E}$ \\
OB & $39( \pm 1.96)$ & $\mathrm{D}$ \\
VF & $44.3( \pm 1.03)$ & $\mathrm{C}$ \\
OF & $53( \pm 4.53)$ & $\mathrm{A}$ \\
OS & $52.5( \pm 1.01)$ & $\mathrm{AB}$ \\
\hline St* Similar letters are not are not significantly different $(\mathrm{p}>0.05)$ &
\end{tabular}




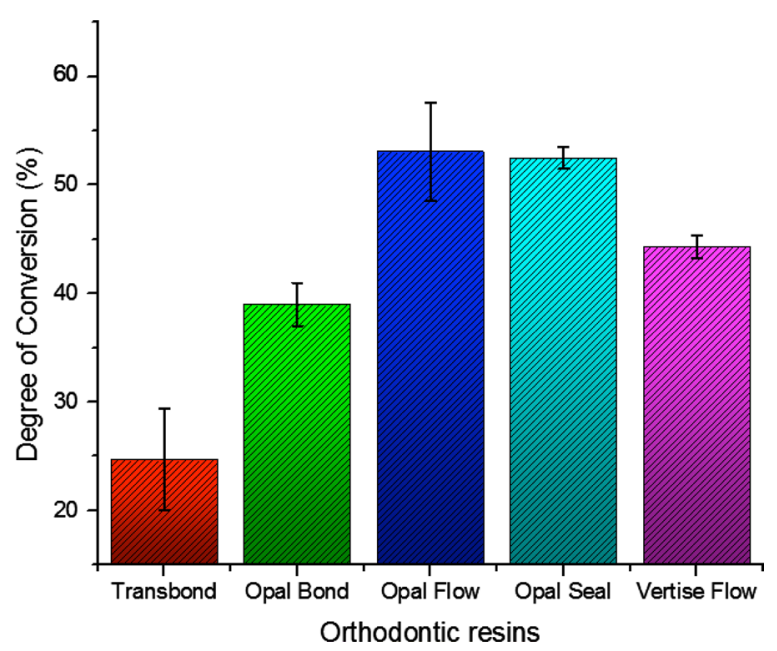

Fig. 2 Mean and standard deviation for degree of conversion (\%) of 5 orthodontic resins

VF, or between VF and OS. However, mean values for OB and OS were significantly different. OF showed the highest mean DC value that was significantly different from all the other systems tested, except OS.

\section{Discussion}

This study assessed the quantity of residual non-reagent monomers right after the polymerization of orthodontic resins that are available on the dental market. It was found a correlation between the DC and the degree of viscosity for the materials tested.

Among other techniques, FTIR is an efficient and widely used to verify the DC [5, 8, 9]. However, this method has limitations. The FTIR does not allow assessment of the depth of cure; that is, differences in the polymerization level between different parts of the sample are ignored [10]. In this study, the DC \% values reported are averages from the top layers of each orthodontic adhesive tested.

The $\mathrm{DC}$ or degree of polymerization of the aliphatic $\mathrm{C}=\mathrm{C}$ in a given orthodontic adhesive is an important factor because it affects the physical and mechanical properties of these materials such as hardness, tensile strength, compressive strength, dissolution (solubility), degradation and biocompatibility [11, 12]. The conversion of monomers is determined by the percentage of the remaining methacrylate groups after curing, when compared to the quantity present in the uncured material [9].

Orthodontic bonding resins, in their polymerized form, are not inert materials [13]. Even when following the manufacturers' recommendations and instructions regarding polymerization, quantities of uncured components can be found and can be leached into the oral environment with the help of saliva. Thompson et al. [13] used UV spectrophotometry to analyse unpolymerized material extracted from cured orthodontic bonding resins in various aqueous solutions. Their findings show that orthodontic resins release considerable quantities of uncured components and that appropriate precautions should be taken when handling these materials.

The chemical composition of orthodontic bonding adhesives is similar to that of dental composites and sealants $[1,13]$. These materials usually contain a mixture of high and 
low molecular weight methacrylate monomer derivatives such as BIS-GMA and TEGDMA, respectively, and also polymerization inhibitors, catalysts and inorganic particles [14]. These components are exposed to oral fluids and they contact oral tissues throughout orthodontic treatment. Although they are widely accepted in modern dentistry, the composition of these materials presents cytotoxic properties that can be hazardous to patients' health [13, 15-17]. Studies show that monomer leaching from resins can occur at two time points: during the resin setting period and when the resin is degraded [18]. Monomer leaching at the first time point is related to the degree of conversion.

The data obtained in this study is in agreement with published findings, which indicate that different materials have different percentages of remaining methacrylate groups after light curing (i.e. different DC values) [14]. The differences found in conversion values could be attributed to variation in resins composition, in terms of monomeric systems, type and quantity of load particles, concentration of diluents and initiators [19]. The percentage of chemical conversion in the orthodontic resins analyzed decreased within a range of $24.6-53 \%$, which is in contrast to the range of $55-75 \%$ that was reported in other studies [20-22]. Ferracane and Greener [27] studied unfilled BisGMA-based dental resins that had a DC ranging from 55 to $72 \%$. Data related to the TR system, which showed the lowest DC \% value, was similar to the findings of other studies that tested the same resin for cytotoxicity and DC [19, 23]. Two resins from Opal Orthodontics, the OF and OS, showed the highest DC \% values, but there was no statistical differences among the resins. These two are low viscosity resins, and the OS is a fluoride-releasing orthodontic sealant, which is intended to protect the dental surface that will receive the bracket. To date, there are only a few studies on the Opal Orthodontics' resins [24]; one of these studies was by Hess et al. [25], who studied the decalcification phenomenon of the dental structure during orthodontic treatment.

Correlating the DC \% values and the viscosity of the materials investigated, the highest DC mean values were found in the low viscosity samples, suggesting a relationship between the DC and viscosity of materials. The filler content and the viscosity of resins may interfere in the monomer conversion, because they can limit the mobility of monomers and propagation of the polymerization reaction [26]. The lower viscosity of resins allows better monomeric mobility and distribution of free radicals inside the material, which can enhance the polymerization process leading to a greater monomer conversion [27]. Because of this principle, low viscosity composites may allow enhanced diffusion of reactive groups and promote the curing reaction, resulting in a higher DC [27]. In addition, lower viscosity composites have been shown to adequately bond to enamel without requiring an intermediary resin, and they also have the ability to infiltrate acid-etched enamel to form a strong bond $[28,29]$.

The findings of this study showed the degree of polymerization of some commercially available orthodontic resins and determined an association with the material viscosity. However, further laboratory and clinical studies are recommended to analyze other properties of orthodontic resins, especially the flowable type.

\section{Conclusions}

Among the tested resins, the low viscosity resins had a higher DC, which can indicate a lower toxicity. This may be because of a potentially low residual monomer elution, 
resulting in a lower health risk and a better choice of material to be used in clinical practice.

\section{Authors' contributions}

LOFA: performed the experiments in partial fulfillment of requirements for a degree, wrote the manuscript, performed a certain test. OB: Idea, proofread the manuscript. AAMM: Proofread the manuscript, contributed substantially to discussion. RF: Idea, hypothesis, experimental design, contributed substantially to discussion, drafting and revising it critically. All authors read and approved the final manuscript.

\section{Author details}

${ }^{1}$ Faculty of Dentistry, Universidade Federal de Sergipe, Avenida Marechal Rondon, Jardim Rosa Elze, São Cristóvão, SE CEP: 49100-000, Brazil. ${ }^{2}$ Orthodontics Division, College of Dentistry, Faculty of Health Sciences, University of Manitoba, D232 Dental Building, 780 Bannatyne Avenue, Winnipeg, MB R3E OW2, Canada. ${ }^{3}$ Dental Biomaterials Research Lab, Department of Restorative Dentistry, College of Dentistry, Faculty of Health Sciences, University of Manitoba, D232 Dental Building, 780 Bannatyne Avenue, Winnipeg, MB R3E 0W2, Canada.

\section{Competing interests}

The authors declare that they have no competing interests.

Received: 12 November 2015 Accepted: 13 December 2015

Published online: 22 December 2015

\section{References}

1. Rahiotis C. Degree of cure and monomer leaching from orthodontic adhesive resins. In vitro and in vivo evidence. Semin Orthod. 2010;16(4):266-73.

2. Eliades T, Viazis AD, Eliades G. Bonding of ceramic brackets to enamel: morphologic and structural considerations. Am J Orthod Dentofac Orthop. 1991:99:369-75.

3. Lekka MP, Papagiannoulis L, Eliades GC, et al. A comparative in vitro study of visible light-cured sealants. J Oral Rehabil. 1989:16:287-99.

4. Tecco S, Traini T, Caputi S, Festa F, de Luca V, D'Attilio M. A new one-step dental flowable composite for orthodontic use: an in vitro bond strength study. Angle Orthod. 2005;75:672-7.

5. Ajaj R, Baier R, Fabiano J, Bush P. Infrared spectroscopic analysis of restorative composite materials' surfaces and their saline extracts. Prog Biomater. 2013;2:9.

6. Lee SY, Huang HM, Lin CY, Shih YH. Leached components from dental composites in oral simulating fluids and the resultant composite strengths. J Oral Rehabil. 1998;25(8):575-88.

7. Schweikl H, Spagnuolo G, Schmalz G. Genetic and cellular toxicology of dental resin monomers. J Dent Res. 2006:85(10):870-7.

8. Hedzelek W, et al. Infrared spectroscopic identification of chosen dental materials and natural teeth. Acta Physica Polonica. 2008;114(2):471-84.

9. Moraes LGP, Rocha RSF, Menegazzo LM, de Araujo EB, Yukimito K, Moraes JCS. Infrared spectroscopy: a tool for determination of the degree of conversion in dental composites. J Appl Oral Sci. 2008;16(2):145-9.

10. Shinya M, Shinya A, Lassila LVJ, Varrela J, Vallittu PK. Enhanced degree of monomer conversion of orthodontic adhesives using a glass-fiber layer under the bracket. Angle Orthod. 2009;79(3):546-50.

11. Sangwoo K and Jyongsik J. The measurement of degree of conversion for BIS-GMA/silica composites by FT-IR spectroscopy. Polym Test. 1996;9418(96):559-71.

12. Eliades T, Eliades G, Brantley WA. Polymerization efficiency of chemically cured and visible light-cured orthodontic adhesives: degree of cure. Am J Orthod Dentofac Orthop. 1995;108(3):294-301.

13. Thompson LR, Miller EG, Bowles WH. Materials science: leaching of unpolymerized materials from orthodontic bonding resin. J Dent Res. 1982;61(8):989-92.

14. Ruyter IE, Cyorosi P. An infrared spectroscopic study of sealants. Scand J Dent Res. 1976;84:396-400.

15. Çörekçi B, Malkoç S, Öztürk B, Gündüz B, Toy E. Polymerization capacity of orthodontic composites analyzed by Fourier transform infrared spectroscopy. Am J Orthod Dentofac Orthop. 2011;139(4):e299-304.

16. Rathbun MA, Craig RG, Hanks CT, Filisko FE. Cytotoxicity of a BIS-GMA dental composite before and after leaching in organic solvents. J Biomed Mater Res. 1991;25:443-57.

17. Olea N, Pulgar R, Perez P, Olea-Serrano F, Rivas A, Novillo-Fertrell A, et al. Estrogenicity of resin-based composites and sealants used in dentistry. Environ Health Perspect. 1996;104:298-305.

18. Sunitha C, Kailasam V, Padmanabhan S, Chitharanjan AB. Bisphenol A release from an orthodontic adhesive and its correlation with the degree of conversion on varying light-curing tip distances. Am J Orthod Dentofac Orthop. 2011;140(2):239-44.

19. Pithon M, Santos R. Evaluation of cytotoxicity and degree of conversion of orthodontic adhesives over different time periods. Mater Res. 2010;13(2):165-9.

20. Kauppi MR, Combe EC. Polymerization of orthodontic adhesives using modern high-intensity visible curing lights. Am J Orthod Dentofac Orthop. 2003;124(3):316-22.

21. Eliades GC, Vougiouklakis GJ, Caputo AA. Degree of double bond conversion in light-cured composites. Dent Mater. 1987;3:19-25

22. Ferracane $J \mathrm{~L}$, Greener $\mathrm{EH}$. The effect of resin formulation on the degree of conversion and mechanical properties of dental restorative resins. J Biomed Mater Res. 1986;20:121-31. 
23. Jagdish N, Padmanabhan S, Chitharanjan AB, Revathi J. Cytotoxicity and degree of conversion of orthodontic adhesives. Angle Orthod. 2009;79:1133-8.

24. Choi RJ. Effectiveness of fluoride containing bonding resins in preventing demineralization of enamel during orthodontic treatment. Doctoral dissertation, University of Louisville. 2012.

25. Hess E, Campbell PM, Honeyman AL, Buschang PH. Determinants of enamel decalcification during simulated orthodontic treatment. Angle Orthod. 2011;81:836-42.

26. Francescantonio M Di, Cavalcanti AN, Davanzo CU. Influence of viscosity and curing mode on degree of conversion of dual-cured resin cements. Eur J Dent. 2013;7:81-5.

27. Ferracane JL, Greener EH. Fourier transform infrared analysis of degree of polymerization in unfilled resins-methods comparison. J Dent Res. 1984;63(8):1093-5.

28. Frankenberger R, Lopes M, Perdigao J, Ambrose WW, Bosa BT. The use of flowable composites as filled adhesives. Dent Mater. 2002;18:227-38.

29. Ryou DB, Park HS, Kim KH, Kwon TY. Use of flowable composites for orthodontic bracket bonding. Angle Orthod. 2008:78(6):1105-9.

\section{Submit your manuscript to a SpringerOpen ${ }^{\circ}$} journal and benefit from:

- Convenient online submission

- Rigorous peer review

- Immediate publication on acceptance

- Open access: articles freely available online

- High visibility within the field

- Retaining the copyright to your article

Submit your next manuscript at $\boldsymbol{\nabla}$ springeropen.com 